\title{
Iskustvo Beograda Augustina Tina Ujevića
}

Abstract: Nowak-Bajcar Sylwia, Iskustvo Beograda Augustina Tina Ujevića (Augustin Tin Ujević's Experience of the Belgrade). "Poznańskie Studia Slawistyczne" 18. Poznań 2020. Publishing House of the Poznan Society for the Advancement of the Arts and Sciences, Adam Mickiewicz University, pp. 145-157. ISSN 2084-3011.

The subject of the analysis in this article are the texts of Augustin Tin Ujević created during his stay in Belgrade. The way of experiencing this city by the poet is reflected through the relationship between the subject and the urban space, through the language of the lyrical expression and through poetics. The interpretive key to its reading is the flaneur figure, treated not as a prototype, but as a reference point.

KEYwORDs: flaneur figure; walking; perception of urban space; inclusion and exclusion

Mada je Beograd snažno otisnuo svoj beleg u životu Augustina Tina Ujevića (on je u glavnom gradu Kraljevine Srba, Hrvata i Slovenaca, zatim Jugoslavije proveo devet godina - od 1920. godine do polovine novembra 1925. godine i od juna 1926. godine do polovine novembra 1929. godine) $)^{1}$, ipak u njegovim književnim tekstovima ima malo tragova Beograda koji su eksplicitni i lako prepoznatljivi. Ti tragovi su utkani u njegovo delo na drugačiji način i nalaze se tek pomnijim istraživanjem i boljim razumevanjem Ujevićeve imaginacije, pa zato mogu biti i značajna odlika njegovog književnog stvaranja. Iako u centru interesovanja ovog članka nisu književni portreti Bograda, već način doživljavanja beogradskog prostora, treba istaći da je pokušaj da se portreti Beograda neposredno izvedu iz Ujevićeve poezije veoma težak zadatak jer se ni u jednoj njegovoj pesmi ne pojavljuje ime ovog grada. Čak i ako pesničko iskustvo Beograda

${ }^{1}$ Detaljan prikaz Ujevićevog boravka u Beogradu, veze pesnika sa književnom sredinom i njegovo prisustvo u kulturnom životu grada, oslanjajući se isključivo na dokumentarnu građu, detaljno je prikazao Nedeljko Ješić (2008) u knjizi Tin Ujević i Beograd. 
potražimo u pesmama sa gradskom tematikom nastalim ili objavljenim tokom Ujevićevog boravka u ovom gradu, ispostaviće se da ih skoro i nema. Beogradski tragovi, međutim, nalaze se u pesmi Sutrusni tramvaji iz 1921. godine (Ujević, 1921, 576-578), eksplicitno u feljtonu Futuristički Beograd (Ujević, 1922a, 3) i Himnika ulica (Ujević, 1922b, 592-595) - oba dela iz 1922. godine. Tekstovi koji su nastali u istom ili bliskom periodu odlikuju se raznovrsnošću, iz njih ne može da se izvede koherentna vizija jednog odrešenijeg grada ili jednistvenog lirskog, čak ni samo saznajnog subjekta koji ga doživljava, dok neke teme Ujević razvija tek u pesmama napisanim tridesetih godina. U tom slučaju, kada se pogleda celina saodnosa ovih pesama, vidi se jedna celovitija urbana poetska vizija. Pozicija eksplicitne pesničke referencije, veze između stihova različitih pesama koji dele jednu vrstu referencijalnosti i manifestni karakter govora o Beogradu, sve to ovaj pesnički urbani vidik čini utemeljenijim i obavezujućim izazovom za tumačenje. To, naravno, nipošto ne umanjuje opštost poetičkog karaktera grada i univerzalnost urbanosti pesničke vizije, već upućuje na intrigantno interkulturalno povezivanje i književnoistorijsku dinamiku jednog zajedničkog prostora koji je u međuvremenu uglavnom ili sasvim iščezao.

Predmet analize u ovom izlaganju je, kako sam već spomenula, način doživljavanja grada koji se odražava u kreaciji subjekta (relaciji subjekt grad), u jeziku lirskog iskaza i poetici. Interpretativni ključ za čitanje ove poetike je figura šetača posmatrana ne kao prototip već kao predmet poređenja. Izbor ove interpretativne alatke opravdava činjenica da je doživljaj Pariza bio ključan za formiranje paradigmatske vizije gradskog prostora koja se snažno odrazila u Ujevićevom stvaralaštvu i pesnikovom tekstu (stilu) života (Kojen, 2004; Stamać, 1971). Ipak, način doživljavanja gradskog prostora u delu hrvatskog pesnika ne može se isključivo izvesti iz tog pariškog iskustva. Odlomak feljtona Futuristički Beograd sadrži eksplicitnu sliku tadašnje jugoslovenske prestonice koja se znatno razlikuje od gradskih pejzaža u znaku velegradskog splina²:

${ }^{2} \mathrm{Ovu}$ vrstu promene možemo posmatrati kao prelaz iz modernističke stilske formacije prema avangardi. Interesantan prilog ovom problemu, koji se takođe razmatra pomoću figure šetača, jeste tekst Kristine Pjenjonžek-Marković, Između moderne $i$ avangarde - Himnika ulice Tina Ujevića (Pieniążek-Marković, 2019, 35-44). 
Futuristički Beograd se najlakše primjećuje u blizini kafane Moskve: to je ovaj čitav svijet, to je ovaj čitav svijet koji se okreće u vrzinom kolu, vitla u danteovskim kovitlacima, te koji prvi požudno guta svaku novost, svaki nemir. [...] Poezija brzine, ekspanzije, elektriciteta sa šumom motora. Futuristički Beograd nije od samih Beograđana, ima tu i makedonskih ,bugaraša ${ }^{e e}$, i bosanskih muslimana, i crnogorskih partikularista; ima i serdarskih gorštaka, i Vojvođana, i Hrvata i Dalmatinaca, i svih vrsta prečana; ima i raznoplemenih došljaka van granica države. Ovo šarenilo, pomiješano sa nekim egzotizmima, stvara neku jedinstvenu vrevu; treba priznati da dobri živci i zdravlje od željeza mnogo pomažu u ovoj žurbi gomile. Slabiji bi čovjek u guranju za nedjelju dana poludio. Za punoću slike mnogo doprinose tramvaji koji sa zvonkanjem i treštanjem odmiču preko Terazija; a automobili bez broja čine bitan dio ovoga uživanja. Bijeli, crni, smeđi i zeleni automobili slave pobjedu pare i benzina nad konjem koji otupjelo vuče fijaker. Tako se stvara jedan novi dinamički često i bombastički svijet, ne možemo da kažemo na ruševinama starine jer je ovdje nikako i nema kao u Grčkoj i Rimu, potpuno prevazilazeći sva poimanja g. g. Rakića i Dučića (Ujević, 1991e, 71).

Ova slika dinamike beogradskog kosmopolitskog života najavljuje promenu načina doživljavanja grada koja se desila tokom Ujevićevog boravka u Beogradu. Ona podrazumeva napuštanje frankofonskih inspiracija epohe i tradicije oličene u delima i drugih spomenutih pesnika srpske moderne ${ }^{3}$.

Ako pretpostavimo da se u figuri flanera odslikavaju modernizacijski (civilizacijski) procesi, nije teško primetiti da je ona sama kao njihov medij bila podvrgnuta promenama. Ova figura je bila znak novog položaja subjekta u modernom svetu. Njeno savremeno razumevanje lapidarno je formulisao Hajnc Pecold, koji je konstatovao da je flaner „figura modernog subjektiviteta oblikovanog u velikom gradue (Paetzold, 1998, 122). Sada se u njoj susreću najrazličitija značenja, a njihova količina je prouzrokovana činjenicom da je od XIX veka, kada je - zahvaljujući Bodleru -

${ }^{3} \mathrm{O}$ Ujevićevim inspiracijama srpskom modernom piše Julijan Kornhauser u članku $A u$ gustin Ujević a serbska Moderna (Kornhauser, 2005) pozivajući se na Leona Kojena, koji je prvi ukazao na ove inspiracije. Ipak treba istaći da je feljton Futuristički Beograd vrsta manifesta koji registruje proces (delimičnog) i nedoslednog napuštanja stilske formacije koju su zastupali pesnici srpske moderne. Ovu činjenicu potvrđuje Ujevićev tekst Čuda neba i blaga zemlje iz 1922. godine (Ujević, 1922c), objavljen u „Novostima"e i posvećen Stanislavu Vinaveru, u kojem čitamo: „Mi smo već od godine 1914. izvršili u poezji, a gotovo i u prozi, jednu revoluciju koja je vrlo znamenita, mada je još svi ne vide i neće da priznadu. [...] Ali od sveta tradicionalne naše poezije, a naročito od grupe Rakića i Dučića, mi smo već prilično poodmakli. To bismo isto mogli kazati i za Pandurovića i za Disa i za Svetislava, a tako paralelno i za A. G. Matoša, Vladimira Nazora, Ivu Vojnovića i Dragutina Domjanićae (Ujević, 1991d, 375). 
započela figuracija flanera, ova kategorija inspirisala istraživače književnosti, kulture, estetike, filozofe i sociologe (Rybicka, 2003, 158; Szalewska, 2012, 44-45). Raznolikost flanerovih obličja, koja je posledica napora mnogih interpretatora modernizacijskih procesa (od Valtera Benjamina, Franca Hesela, Zidfrida Krakauera ili Georga Zimela) sve do naših vremena (Zigmunt Bauman), doprinosi tome da figura flanera postaje veoma zgodna alatka za interpretaciju Ujevićevih dela. Polazna tačka predloženog čitanja Ujevićevog grada je zapažanje Kristofera Prendergasta da „flaniranje nije bilo samo gradski običaj, društvena praksa, već i stav, metod za spoznaju i posmatranje grada, koji je određivao narativnu ili lirsku situaciju modernog diskursa o gradu "e (Prendergast, 1992, 134).

Flaner je figura - vrsta subjekta, čija je odlika šetnja, neužurban pokret, pešačenje, posmatranje na način da se ostane neprimećen, što je jedan od načina posedovanja vlasti. Flaner je umetnik koji „ume da verbalizuje iskustvo savremenosti. [...] Njega više ne legitimizuju uzvišena dela već svakidašnjica, privremenost koja zamenjuje večne vrednosti ${ }^{\text {¿e }}$ (Szalewska, 2002, 46). Valter Benjamin konstatuje: „Flaner je sveštenik takozvanog genius loci. On je neupadljiv prolaznik opremljen svešteničkim dostojanstvom i detektivskim osećajem ${ }^{\text {ee }}$ (Benjamin, 2001, 273). Umetnost šetnje je poznata Ujeviću, o čemu svedoči njegov svojevrsni pesnički manifest Himnika ulica, napisan u Beogradu 1922. godine, u kojem čitamo:

I to je veština, šetati se. Nekada vidite tako zanimljivih lubanja, neku živu suknju ili zamamnu kabanicu, a nekada takve glave kakve ste vidjeli samo u snima. I mislite da ste u raju. A onda opet putevi, raskršća, trgovi, kola, kočije i tramvaji, sa dosadom vašega bića i maglom vaših misli. I pored dubokog očajanja moje samoće, ja uživam u ovoj vrtoglavoj anarhiji gdje mogu da se slobodno krećem po ulici, da pušim cigaretu, ili da mislim što hoću: naime i ništa, ako se može tako (Ujević, 1970, 367).

Ipak, uprkos svesti o značaju šetnje i nesumnjivog poznavanja Bodlerovih tekstova u kojima je predstavljen flanerov prototip, junak Ujevićevih pesama često nije i ljubitelj šetnji. Štaviše, on se ne šeta, a kao što ističe Valter Benjamin, flanerovu percepciju urbanog prostora upravo određuje zanos koji je posledica kinetičkog pokreta tela. „Toga ko dugo i besciljno

\footnotetext{
${ }^{4}$ Reinterpretacije ove figure vode čak i negiranju prvobitnih značenja koje se u nju upisuju i zato npr. Katažina Šalevska piše o reinterpretacijama koje u suštini bolje opisuje pojam antiflanerizma (Szalewska, 2012, 48-49).
} 
luta ulicama - piše - obuhvata opojnost (Rausch), koja raste sa svakim sledećim korakom" (Benjamin, 1991, 525). Određujući svoju ulogu kao posmatrača, posetioca kafana, čoveka koji se distancira i pripada drugom svetu, lirski subjekt izražajno ističe svoju otuđenost u gradskoj stvarnosti. Mada je ovo distanciranje, naravno, upisano u autokreaciju flanera, lirski subjekt Ujevićeve pesme je statičan, njegov položaj ostaje spoljašnji u odnosu na svet koji predstavlja, a tempo doživljaja nije usklađen sa ritmom grada. U pesmi Stihovi su postali grad iz 1933. godine on se obraća flaneru savetujući ga:

\footnotetext{
Sine nedelje, i ti, druže večernje šetnje, izađi na korzo u svom boljem odijelu, prouči svoje zavodničke kretnje i sanjaj, za te čase, kroz noć cijelu o svom arhanđelu u ženskom tijelu (Ujević, 1991b, 38),
}

dok će on sam, kako kaže, da deli „te radosti iste / od jedne kaplje čiste (Ujević, 1991b, 38), ističući da je za njega kafana mesto kojem pripada i sa kojim se indentifikuje, dok je alkohol supstitut šetnji koje ga vode u prošlost: „Tu sam, - konstatuje - s glavom na laktima uprtim na stolu, iz reda čaša i flaša, pred pepeonikom, sjetio se (onda bosonog!) na prvu osnovnu školu pod kakvim tihim seoskim zvonikom (Ujević, 1991b, 36).

Junak Ujevićeve pesme posmatra haos nove, dinamične stvarnosti, ali u njoj ne učestvuje, suprotstavljajući grad - negativno vrednovan prostor vladavine zakona jačega: „Tu su orlovi pobedili slavuje ee ,Što će, za miloga boga, tu zalutale ptice / no da svisnu, s ledom, plašljiva srca, sred tmi-

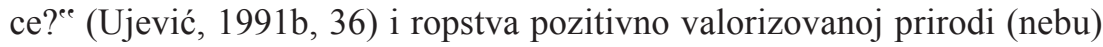
- prostoru neograničene slobode čiji su gospodari ptice. „Da nije u grad proze zabranjen ulaz nebu? (Ujević, 1991b, 38) - pita Ujevićev lirski subjekt. Autobiografski tragovi koje on navodi predstavljaju nostalagičnu restituciju prošlosti i istovremeno registruju proces nestajanja mesta. Dvoumeći se između prošlosti čije tragove/slike nosi u sećanju i sadašnjosti koja se dinamično gradi/događa pred njegovim očima, lirski junak Ujevićeve pesme iskazuje melanholičnu refleksiju o gubitku onoga što je otišlo, potvrđujući svoje umeće dvostrukog sagledavanja: u prošlost i u sadašnjost. Njegova egzistencija je anahrona, ona pokušava da spase ostatke 
svog sveta. Dok svom drugu savetuje šetnju, rečima: „A ja ću sam uživati kretnju polimetra"e (Ujević, 1991b, 36) lirski junak pesme Stihovi su postali grad ograđuje se od spoljašnjosti istovremeno ističući iskustvo raznolikosti brzine života grada, njegovog simultanizma, nagomilanih senzualnih utisaka i usporenog ritma unutrašnjih doživljaja, izazvanih refleksijom koja je usmerena prema prošlosti. Ova interesantna pesma registruje proces iskušavanja istorijskog preokreta, koji je po Benjaminu zamena iskustva doživljajem - vrstom šoka koji se zasniva na tome da događaj dopire do svesti samo delimično i gubi vezu sa drugim pojavama a time svoje mesto u vremenu i prostoru (Benjamin, 1970, 74; Sauerland, 1986, 149). Savremeni čovek koji je izložen gomili stimulanasa zastupa drugačiji stav nego što je to činio ranije - ne uključuje ih u sistem znanja građen na osnovu iskustva, već im predviđa mesta koja se slobodno povezuju sa drugim sadržajem u memoriji. Do sličnog zaključka došao je Georg Zimel, čija analiza rađanja velegradskog intelektualizma posmatra svest kao organ koji štiti od promenljive spoljašnje i heterogene sredine. Intelektualizam je, dakle, po njemu sredstvo zaštite subjektivnog života od nadiranja velikog grada. Nagomilavanje slika koje se menjaju, nekoherentnost i raznolikost impulsa koji bombarduju svest pruža „svaki prelazak ulice, posmatranje tempa i mnogostrukosti privrednog, profesionalnog i društvenog života ${ }^{e e}$, kaže Zimel (Simmel, 2005, 306).

Junak Ujevićeve pesme povlači se iz vreve života, bira samoću. Mada Benjamin, osim „opojnosti ${ }^{i e}$ izazvane šetnjom i pokretom tela (čega u Ujevićevim pesmama nema), ističe flanerovu alijenaciju kao njegovu odliku (On je - piše Pecold [Paetzold, 1998, 123] - ,stranac, čovek spolja koji nema u gradu svoju »otadžbinu«, ali ga on uzbuđuje ${ }^{e c}$ ), treba istaći da se kako je primetio Hans Robert Jaus, kritikujući Benjaminovu reinterpretaciju figure Bodlerovog flanera - „ovaj moderni lik lirskog subjektiviteta ne uklapa u perspektivu otuđenog čovekae (Jauss, 1999, 54). Pridružuje mu se Hajnc Pecold. „Stanovnik modernog grada - piše - lišen je luksuza usamljeničke vita contemplativa, a i zona javnosti grada nije zona dijaloga ${ }^{\text {ee }}$ (Paetzold, 1998, 123).

Ipak, takav subjekt nije jedini koji se pojavljuje u Ujevićevim pesmama. Lik distanciranog umetnika čije je mesto „nebo u prostoru iznad/van stvarnosti pojavljuje se uporedo sa drugim vrstama subjekata. Lirski junak sa jedne strane zauzima stav statičnog posmatrača, 
što je izazvano potrebom očuvanja nezavisnosti, vrsta je nonkonformističke (auto)kreacije, ali sa druge strane izražava za flanera karakterističnu potrebu za - (privremenom) identifikacijom sa drugošću/stranošću (gomilom). Na taj način se manifestuje strategija bivanja-u-svetu - samoće kao otuđenosti i odomaćivanja, koja se događa na planu potrebe za identifikacijom i antagonističkim stavom (Szalewska, 2012, 77).

Ova dihotomija se ispoljava kroz način na koji se Ujevićev lirski junak poistovećuje sa univerzumom gradskog prostora, kroz proces konfrontacije ,ja ${ }^{\text {ee }}$ i „mi mie. U pomenutom eseju Himnika ulica Ujević piše:

Mi smo vezani za svoje siromašne sobe, a iz njih izvirujemo katkada kao miševi i krtice na ovu blijedu gradsku svijetlost. Bolji i slobodoumniji pogled na zvijezde nama je zabranjen i ukraden. Vezani smo svojim bićem i svojim radom, i umom, ako ne potpunim srcem, uz grad, ali mi volimo grad kao jedan zlatan lanac. Mi smo poezija grada, makar i sa njegovim zarobljenima. I mi kažemo smjelo narodu: uđi u grad, to jest u obrazovanost i budućnost! Nama je ulica sveta. Mi smo poezija ulice, to jest prometa, industrije, misli, borbe, napretka (Ujević, 1970, 368).

Citirani odlomak svedoči o prevazilaženju otuđenosti koju izaziva grad, pomirenju s njim zahvaljujući uočavanju njegovog društvenog, estetskog i kulturotvornog značenja, ali i o pesnikovom prihvatanju uloge vodiča po ovom prostoru, sebe kao osobe koja saoseća deleći sudbinu najsiromašnijih društvenih slojeva.

Ovaj umetnički manifest koji najavljuje izlazak (iz kafane) na ulicu odražava se i u Ujevićevim pesmama. U jednoj od njih pod naslovom Ulični pjevači iz 1933. godine Ujević (1991b, 39-40) problematizuje sudbinu pesnika osuđenog na usamljenost i egzistenciju na društvenoj margini, koji se identifikuje sa socijalnim otpadnicima, beskućnicima, čiji je dom - ulica. Pesnici su, dakle, ne samo ulični pevači, pevači (sa) ulice već i njen glas. Mada je ulica pesnikovo mesto, mesto bivanja-u-gradu, ipak se ne radi o afirmaciji tog stanja jer je u pesmi grad (centar) izražajno suprotstavljen predgrađu: „slikaćemo gradu predgrađa u smradu“e (Ujević, 1991b, 39), a oba mesta suprotstavljena prirodi. Mada sudbina preodređuje pesnikovu pripadnost zoni mraka, tame i noći, ,srce vruće ${ }^{e e}$ vodi ga prostoru života, aktivizma. Životni put umetnika je rascep između želje i snova o slobodi. Pesnici pevaju (rade) noću, kada u „san mrtvački pada život tupiee, dok danju sanjaju o umetničkoj slobodi i o poeziji oslobođenoj društvenih 
obaveza. Zemlja (priroda) koja je njihovo sklonište kontrastira sa gradskim prostorom: „Spavat ćemo danju na krilu djevice majke, mlade zemlje, dok se ševice u vis plavi krile, učiteljke, pjevice (Ujević, 1991b, 40).

Priroda u koju se sklanja subjekt Ujevićevih pesama pre je prostor lutanja koji se ne podudara sa enterijerima muzeja, kafana, biblioteka i ritmom života dinamičnog sveta urbane kulture. Gradski parkovi i enklave zelenila koji se pojavljuju u Ujevićevim pesmama, mada bi trebalo da sačinjavaju strogo određen urbani rekvizitorij, isključeni su iz gradskog prostora. Ipak, sa druge strane, u svom eseju-manifestu iz 1922. godine Himnika ulica pesnik piše:

Ja volim u gradu njegove klupe, stakla, aleje, osvijetljene dućane, radnje, knjižare, tvornice, stanice, škole, bolnice, uredništva, lijepa i ljupka šetališta. Za volju toga mu praštam i prašinu i blato, i veliku bijedu ljutih zima sa nedjelima skupoće. Kada bih mogao, oprostio bih i tvrdoću srca građana, poslodavca i stanodavaca, no da li se to može? (Ujević, 1970, 368-369)

U strategijama identifikacije i isključivanja veoma je važno posmatranje grada, a u tom procesu ključnu ulogu igra vid. U pesmi Oblak u prozorskom staklu iz 1932. godine lirski junak gleda svet koji se naopačke ogleda u staklu otvorenog prozora:

\author{
S glavom natraške preko kanapea \\ u ogledalu rastvorena stakla \\ gledam na svijet naopako, s lijeva: \\ nebo, s oblakom kao mala magla (Ujević, 1991c, 193).
}

Okretanje perspektive izaziva promenu položaja lirskog subjekta pesme, koji počinje da gleda oblake odozgo, situirajući se van stvarnosti. U svetu posmatranom u staklenom odrazu on plovi na oblaku prema izgubljenom nebu-moru naseljenom albatrosima. Bez obzira na to što je prozor otvoren, lirski junak pesme gleda sliku stvarnosti. Predočena poetika percepcije registruje svest o posredovanom načinu na koji je svet dostupan čoveku. Ova svest - po mišljenju Rišarda Niča - određuje ključnu promenu načina iskušavanja/doživljavanja stvarnosti koja se odigrala u modernizmu i koja se ispoljava preko odstupanja od realizma, preko alegorizacije i percepcijskim tehnikama, a zasnovana je na tome da „Iskustvo - kako piše Nič - gubi status direktnog znanja o stvarnosti, postajući ne samo 
sinonim neizbežne medizacije čovečjeg kontakta sa stvarnošću već i poprimajući oblik indirektne stvarnosti koja posreduje, zaklanja, štiti ili izoluje čoveka od stvarnosti in crudo (Nycz, 2006, 59). Zahvaljujući tome „,u književnosti i umetnosti ovog razdoblja predmet predstavljanja nije više društveno objektivizovana stvarnost, već njena doživljavana opservacija i razumevanje, personalizovana, kontekstom uslovljeni oblici njenog čulnog iskušavanja i doživljavanja, načini idejne kategorizacije i diskurzivnog opisa i interpretacije ee (Nycz, 2006, 59).

Konstruisanje polja opservacije zasniva se na igri providnosti i prepreke, na mogućnosti da se vidi (zahvaljujući providnosti) i nemogućnosti da se dopre do stvarnosti koja se nalazi iza prepreke. Motiv gledanja odraza vrši veoma važnu simboličku funkciju: prozorsko staklo postaje ekran u kojem lirski subjekt posmatra svoju alternativnu izmaštanu biografiju. Istu ulogu ima gledanje u lica prolaznika, što je izraz potrage za sobom i svojim identitetom. U pesmi Korzo iz 1932. godine čitamo da: „po glavnim ulicama i keju / čovjek vidi otisnuta u stotinama primjeraka sebe. / Krabuljni ples šetača tvori cijelu alejue (Ujević, 1991c, 194). Grad postaje medij ,jae - lirski subjekt prepoznaje sebe u licima šetača, posmatranje grada i gomile vodi identifikaciji s njima, postaje čin (samo)spoznaje ali i pretvaranja/mimikrije/insceniranja, čiji je cilj da se ,zaglušuje biće našem jaduee $\mathrm{i}$ „smrtonosan flert”. Temu flerta Ujević nastavlja u pesmi Među spratovima opisom ,razmene pogleda" koja se vrši između spratova zgrada. Atmosfera vedre noći koja odiše toplim erotizmom, slike gradskog prostora koji se ispunjava plesačima, muzikantima i šetačima podudara se sa Ujevićevom refleksijom iz eseja Himnika ulica, teksta nastalog u beogradskom periodu:

Ali ništa lijepo - pjesnik kao njegov korzo, osvijetljen u blagim prazničnim večerima sa mnogo svjetla i stvoren za prijatan dodir i blago očijukanje. Narod koji nema plesnih forama za flertove tu rasipa elektricitet svojih pogleda.

Ulica živi svojim životom. Kroz šarenilo i modernost vreve ona pruža stotinu novih izgleda na današnjega čovjeka. Jer je građanin samo onaj koji umije da se šeta i da korača kao čovjek, pored neprilika obuće ili odijela. No za to vrijeme ulica nam pruža jedan jedinstveni igrokaz koji neprestano traje sa neizmjerno mnogo prizora. Ulica je veliki i živi bioskop, sa svom sinematikom spontanosti. Treba znati razumjeti ulicu i opažati je. Ja tako vidim šetalaca koji su sposobni da mi pogledom ili migom saopće debele romane, ili prolaznica kojih mučaljivi osmijeh ilustruje dušama naime bolje nego čitav razgovor. Jedan pozdrav ma koji drugi pokret 
dočarava čitave svijetove. A ta se pantomima ulice pretvara u čitave dramske jezike, u velike značajne razlike. Treba razumjeti ulicu, jer je to jedan viši stepen ljudske mudrosti. To su pokušali naturaliste, to će možda da izvrše neofuturiste. Ulica glumi, često bolje no pozorište. Ali ulica i živi, osjeća i voli (Ujević, 1970, 369).

Izlazak na ulicu, identifikacija sa njenim stanovnicima označava svest o novim zadacima pesnika i angažovanost. Umetnik koji izlazi iz unutrašnjosti (kafane) na ulicu nije više posmatrač urbanog života već i njegov učesnik i tvorac, što se ispoljava u nestajanju kontemplativne ili eskapističke distance prema stvarnosti, ali i u književnoj inovantnosti, izlasku van petrifikovanih pesničkih konvencija. Ovaj tip subjekta određuje nove oblike doživljavanja stvarnosti, označava odomaćivanje ulice, što utiče na činjenicu da pasivni posmatrač postaje reditelj ulične stvarnosti koji u njoj učestvuje i koji je gradi (kreira). Na planu jezika umetničkog iskaza ovaj izlazak (svojevrsna transgresija koju simbolički predstavlja metafora Benjaminovih pasaža) označava napuštanje alegorične poetike i prelaz ka poetici percepcije (Rybicka, 2002, 94), dakle prelaz od kontemplativnog posmatranja grada ka uronjenosti u percipirani predmet.

Ipak, čak i u pesmama u kojima Ujević koristi poetiku percepcije ne pojavljuje se šetnja kao preduslov flaniranja. Lirski subjekt opija se brzinom i dinamikom života tokom vožnje tramvajem ili automobilom, registrujući senzualni doživljaj procesualnosti, promene, privremenosti. Kada prolazi autom kroz korzo, ponovo priziva prošlost u autobiografskom pasusu koji se nadovezuje na detinjstvo. Ipak lirski subjekt stavlja uspomene na detinjstvo u sasvim drugačiji kontekst, kontekst koji ne vodi kontemplaciji prirode kao izgubljene vrednosti (kao u ranije navedenoj pesmi Stihovi su postali grad), već upućuje na budućnost industrijalizacije: „Asfalte! asfalte! glavna sirovino moga rodnog sela (Ujević, 1991a, 191). Priroda nije više zaklon, skrovište, kao u ranije predstavljenim pesmama, već se poistovećuje sa gradom postajući objekt ljudskog delovanja. To je priroda koju je čovek savladao, koju prerađuje i crpe iz nje.

Kao i u drugim pesmama, gde se lirski subjekt distancira od spoljašnjeg sveta, u pesmi Autom kroz korzo automobil postaje njegovo sredstvo očuvanja distance, oklop od gume i metala koji štiti od gomile istovremeno omogućavajući da se održi vlast nad njom. Sa druge strane, čak i odvojen od nje, lirski subjekt ipak je deo ove gomile, on - opijen brzinom - postaje tvorac grada, inženjer pogleda, a time i zavodnik. Čin vožnje je u pesmi 
poistovećen sa zavođenjem a istovremeno i sa činom konstruisanja grada i stvaranjem pesme. Lirski subjekt, zanesen svojom moći i moći mašine, postaje demijurg, pesnik himne budućnosti, pa odatle patetičan i uzvišen stil pesničkog iskaza, koji je jedan od elemenata jezičke estetizacije gradskog prostora, ne u smislu njegovog ukrašavanja/dekorisanja već eliminisanja granica između umetnosti i stvarnosti.

Elementi transgresije (pasaža) vidljivi su takođe u strategijama somatizacije gradskog prostora, pronicanju subjekta koji opisuje i predmeta opisa, kao što je to slučaj u pesmi Fotoreporter s krilima arhanđela iz 1931. godine (Ujević, 1991b, 55), gde se čin pisanja izjednačava s novinarskim, fotografskim izveštajem u obliku uličnih slika (snimaka) koje se menjaju u kaleidoskopskom ritmu (pesnik kaže o sebi da je ,,automat ogromne slobode..." ). Lirski subjekt-pesnik-fotoreporter obdaren krilima arhanđela uzdiže se u visine umetnosti i lebdi iznad zemlje, brinući se o zemlji sa kojom saoseća - on i čovečanstvo (identifikacija sa gomilom) jedno su telo (,u mom vrućem srcu tvoje srce tuče e). Ovde predstavljena somatizacija pesničkog iskaza povezuje se ne samo sa subjektivizacijom lirskog govora i uvođenjem lične perspektive već pre svega označava napuštanje predstavljanja topografije koja se prepoznaje u svakidašnjem iskustvu i prelaz ka kreaciji fantazmatskog, oniričkog ili vizionarskog prostora. Grad kao da ne postoji van svesti i doživljaja, što ima za posledicu da se njegov realitet smrvi. Kada se narušava granica između unutrašnjeg i spoljašnjeg, između halucinacije i percepcije, projekcije i stvarnosti, prostor grada gubi svoj jednoznačan ontički status (Rybicka, 2003, 189-190), kao što je to slučaj u pesmi Sutrusni tramvaji iz 1921. godine (Ujević, 1991c, 85-87). Brzina njihovog pokreta izaziva osećaj plutanja u vazduhu, podizanja iznad zemlje u fizičkom i duhovnom smislu. Grad ne samo što izaziva halucinacije već postaje i iluzija, a izvor ovog ekstatičnog stanja su mašine - ostvaren san o čovekovoj moći spajanja najudaljenijih prostora. Pesma egzemplifikuje već spomenut uticaj modernizacije na stanovnike grada kod kojih je iskustvo zamenjeno doživljajem (Benjamin, 1970a, 74), dakle proizvodnju novog stanovnika grada i istovremeno proces umetničke proizvodnje grada.

U ovom izlaganju navodila sam datume nastajanja pojedinih pesama sa ciljem da ukažem na činjenicu da u Ujevićevom pristupu gradu nije moguće uočiti proces napuštanja simbolističke poetike i okretanja poetici percepcije. Čak i u pesmama nastalim posle odlaska iz Beograda pesnik 
se vraća tipično bodlerovskim motivima i bodlerovskom jeziku. Osim uobičajenih (psiholoških) motivacijskih momenata (Ujevićevo razočaranje) kojima se obrazlaže ovaj „regrese ${ }^{\text {ee }}$ povod za to može biti činjenica da grad i ulica, kako se čini, nisu za Ujevića identični fenomeni. Kada piše o gradu, pesnik kao da govori o njegovoj ideji, o alegoričnom prostoru koji sputava slobodu, nedokučivom i tuđem prostoru. Ulica je za Ujevića relevator doživljaja, a kontakt sa njom vodi neograničenoj slobodi, uspenju. Ulica je simbol aktivizma, životnih impulsa, snage i erotike.

Ova analiza vodi još jednom zaključku koji u ovom momentu mogu da formulišem isključivo u obliku pitanja za koje nemam ili ne želim da dam odgovor: zašto je lirski junak pesama Augustina Tina Ujevića odbijao šetnju gradom?

\section{Literatura}

Benjamin, W. (1991). Passagen-Werk 1. Gesammelte Schriften 5. Hrsg. R. Tiedemann. Frankfurt am Main: Suhrkamp.

Benjamin, W. (2001). Powrót flaneura. O Spacerach po Berlinie Franza Hessla. Przeł. A. Kopacki. „Literatura na Świecie” nr 8-9, str. 234-238.

Benjamin, W. (1970a). O kilku motywach u Baudelaire'a. Przeł. B. Surowska. „Przegląd Humanistyczny" nr 5, str. 69-84.

Benjamin, W. (1970b). O kilku motywach u Baudelaire'a. Przeł. B. Surowska. „Przegląd Humanistyczny" nr 6, str. 105-117.

Dąbrowska-Partyka, M. (1999). Tin Ujević - język międzyprzestrzeni. U: Teksty i konteksty. Awangarda w kulturze literackiej Serbów i Chorwatów, Kraków: Wydawnictwo Uniwersytetu Jagiellońskiego, str. 129-170.

Jauss, H. R. (1999). Tradycja literacka a dzisiejsza świadomość nowoczesności. U: Historia literatury jako prowokacja. Przeł. M. Łukasiewicz. Warszawa: Wydawnictwo Instytut Badań Literackich.

Ješić, N. (2008). Tin Ujević i Beograd. Beograd: Službeni glasnik.

Kojen, L. (2004). Pariske godine Tina Ujevića. U: A. Tin Ujević, Lelek sebra. Beograd: Čigoja, str. 117-182.

Kornhauser, J. (2005). Augustin Ujević a serbska Moderna. W: Pejzaże kultury. Prace ofiarowane Profesorowi Jackowi Kolbuszewskiemu w 65. rocznice Jego urodzin. Red. W. Dynak, M. Ursel, Wrocław: Wydawnictwo Uniwersytetu Wrocławskiego. http://postjugo.filg.uj.edu.pl/ujevic.pdf, 12.06.2019.

Moroń, J. M. (1979). Wczesna proza poetycka Tina Ujevicia. Analiza zawartości światopogladowej. U: Literatury stowiańskie $w$ okresie awangardowego przełomu. Red. Z. Niedziela, Wrocław: Zakład Narodowy im. Ossolińskich, str. 81-92. 
Nycz, R. (2006). Literatura nowoczesna wobec doświadczenia. „Teksty Drugie” nr 6, str. 55-69.

Paetzold, H. (1998). Polityka przechadzki. Przeł. E. Mikina. U: Formy estetyzacji przestrzeni publicznej. Red. J. S. Wojciechowski i A. Zeidler-Janiszewska. Warszawa: Instytut Kultury, str. 117-129.

Pieniążek-Marković, K. (2019). Između moderne $i$ avangarde - Himnika ulice Tina Ujevića. U: Słowiańskie formuly nowoczesności - ideaty i iluzje przemiany. Red. L. Miodyński, Katowice: Wydawnictwo Uniwersytetu Śląskiego, str. 35-44.

Prendergast, Ch. (1992). Paris and the Nineteenth Century (Writing the City). Oxford, Cambridge, Mass.: Blackwell.

Rybicka, E. (2003). Modernizowanie miasta. Zarys problematyki urbanistycznej w nowoczesnej literaturze polskiej, Kraków: Universitas.

Sauerland, K. (1986). Przeżycie i doświadczenie, czyli jeszcze raz o Walterze Benjaminie. U: Od Diltheya do Adorna. Studia z estetyki niemieckiej. Warszawa: Państwowy Instytut Wydawniczy, str. 149-166.

Simmel, G. (2005). Mentalność mieszkańców wielkich miast. W: Socjologia. Przeł. M. Łukasiewicz. Warszawa: Wydawnictwo Naukowe, str. 305-315.

Stamać, A. (1971). Tin Ujević. Zagreb: Kolo.

Stamać, A. (1977). Tin Ujević kao europski pjesnik. U: Slikovno i pojmovno pjesništvo. Zagreb: Sveučilišna naklada Liber, str. 31-63.

Szalewska, K. (2012). Pasaż tekstowy. Czytanie miasta jako forma doświadczania przeszłości we współczesnym eseju polskim. Kraków: Universitas.

Ujević, A. (1921). Sutrusni tramvaji. „Misao” 15.12., knj. VII, sv. 48.

Ujević, A. (1922a). Futuristički Beograd. „Novosti” 17.09., br. 413.

Ujević, A. (1922b). Himnika ulica. „Misao” 16.04., knj. VII, sv. 8.

Ujević, A. (1922c). Čuda neba i blaga zemlje. „Novosti” 2.09., br. 400, str. 3; 3.09., br. 401, str. 3; 6.09., br. 402, str. 3; 9.09., br. 403, str. 3 .

Ujević, A. (1970). Himnika ulica. U: Eseji i kritike. Zapisi II. Ur. Š. Vučetić. Serija: Pet stoljeća hrvatske književnosti, knj. 88, Zagreb: Matica hrvatska - Zora, str. 366-370.

Ujević, A. (1991a). Pjesme I. Sabrana djela, sv. 1. Ur. V. Vidović. Split: Književna izdavačka zajednica Tin Ujević.

Ujević, A. (1991b). Pjesme II. Sabrana djela, sv. 2. Ur. V. Vidović. Split: Književna izdavačka zajednica.

Ujević, A. (1991c). Pjesme III. Sabrana djela. Sv. 3. Ur. V. Vidović. Split: Književna izdavačka zajednica Tin Ujević.

Ujević, A. (1991d). Kritike, prikazi, članci, polemike. Sabrana djela. Sv. 7. Ur. V. Vidović. Split: Književna izdavačka zajednica Tin Ujević, str. 370-377.

Ujević A. (1991e). Feljtoni I. Sabrana djela. Sv. 12. Ur. V. Vidović, Split: Književna izdavačka zajednica Tin Ujević.

Wierzbicki, J. (1992). Wielki Tin. U: Pożegnanie z Jugosławia. 1: Szkice i portrety literackie. Warszawa: Slawistyczny Ośrodek Wydawniczy Omnitech Press, str. 40-57. 